\title{
VOZ CANTADA E A CONSTITUIÇÃO DA RELAÇÃO MÃE-BEBÊ
}

\section{Singing voice and the constitution of mother/baby relationship}

\author{
Enio Lopes Mello ${ }^{(1)}$, Suzana Magalhães Maia (2), Marta Assumpção de Andrada e Silva ${ }^{(3)}$
}

\begin{abstract}
RESUMO
Tema: refletir sobre uma faceta da constituição da relação mãe-bebê, que se fez presente no uso criativo da voz cantada da mãe, na comunicação com o seu bebê. Procedimentos: o único sujeito desse estudo é uma mãe, que se submeteu a oito sessões de terapias corporais associadas à emissão da voz cantada, sempre dirigidas ao bebê; as sessões transcorreram com a possibilidade de expressão livre pela fala e gesto da mãe e a escuta do terapeuta. Resultados: o quadro que a mãe apresentava em relação ao seu bebê, no início do tratamento, se encaixa na descrição de depressão pós-parto. Após as sessões, a mãe conseguiu estabelecer contato com seu bebê, de modo prazeroso; por meio da emissão da voz cantada, ela estabeleceu a primeira forma de comunicação e não mais apresentou o quadro de dor e perda da voz. Conclusão: a possibilidade de reconhecimento, do bebê por sua mãe, teve a corporeidade como aliada, na conjunção dos corpos da mãe e do bebê, o que favoreceu o estabelecimento de uma comunicação com sintonia de ritmos, por meio da entoação de música cantada, que levou à constituição do bebê enquanto pessoa integrada.
\end{abstract}

DESCRITORES: Relações Mãe-Filho; Recém-Nascido; Comunicação; Voz

\section{INTRODUÇÃO}

Este estudo é o relato de uma intervenção terapêutica que visou a integração corpo e voz (principalmente voz cantada), junto a uma mãe, que não conseguia estabelecer vinculo com seu bebê recém nascido, e sofria de padecimentos corporais, manifestados através de dores e perda da voz, todas as vezes que tentava se comunicar com o seu bebê.

Esse é um estado psicológico especial, um modo típico que acomete as mulheres gestantes

(1) Biólogo; Cantor lírico; Terapeuta corporal; Afiliado ao Departamento de Pós-Graduação em Fonoaudiologia da Pontifícia Universidade Católica de São Paulo (bolsista), PUCSP, São Paulo, SP; Especialista em Reestruturação das Cadeias Musculares e Articulares Método GDS pelo Institut des Chaînes Musculaires et Techniques Godelieve Dennys-Struyf, Bruxelas, Bélgica; Mestre em Fonoaudiologia pela Pontifícia Universidade Católica de São Paulo.

(2) Psicanalista; Fonoaudióloga; Professora Titular da Graduação e Pós-Graduação em Fonoaudiologia da Pontifícia Universidade Católica de São Paulo, PUCSP, São Paulo, SP; Mestre e Doutora pela Universidade de São Paulo.

(3) Fonoaudióloga; Professora Titular da Graduação e PósGraduação em Fonoaudiologia da Pontifícia Universidade Católica de São Paulo, PUCSP, São Paulo, SP; Especialista em Fonoaudiologia Clínica e em Voz Cantada; Mestre em Distúrbios da Comunicação; Doutora em Comunicação e Semiótica pela Pontifícia Universidade Católica de São Paulo. no final da gestação e nas semanas que sucedem o parto. Compara-se a uma doença, uma dissociação, um estado esquizóide que é considerado normal durante esse período. A expressão "mãe dedicada comum" designa a mãe capaz de vivenciar esse estado, e desempenhar, naturalmente, as tarefas da maternidade, temporariamente alienada de outras funções, sociais e profissionais, trata-se de uma condição psicológica muito especial, de sensibilidade aumentada ${ }^{1}$.

No entanto, existem exceções! Algumas mães têm dificuldade em oferecer estes cuidados aos seus bebês em função da depressão pós-parto, que é caracterizada por período de risco psíquico aumentado na mulher, que dificulta o estabelecimento de um vinculo afetivo seguro entre mãe e bebê, que pode interferir nas futuras relações estabelecidas pela criança ${ }^{2}$.

$O$ bebê quando nasce é um ser indefeso e incapaz de sobreviver, por meio de seus próprios recursos, portanto, o que lhe falta deve ser suprido por um adulto cuidador. Muito mais do que alimentação e higiene, o bebê necessita de contato afetivo continuo advindo de uma figura constante, com a qual estabelece relações de apego e que assegura e favorece o seu desenvolvimento biopsíquico ${ }^{3}$.

Trabalhos recentes ${ }^{4-6}$, dentro da psicanálise e da fonoaudiologia, têm desenvolvido diferentes 
estratégias de abordagem sobre a comunicação estabelecida entre mãe e bebê. A voz dos pais tem um papel muito importante na determinação do destino da constituição do sujeito, não como atributo específico dos pais, mas como algo cujo emprego depende e determina ao mesmo tempo a dinâmica desta relação.

Em uma pesquisa sobre a prosódia do "mamanhês" ${ }^{4}$ nos bebês normais, concluiu-se que as reações do bebê melhoram a amplitude das curvas da prosódia na mãe. Esta prosódia é, portanto, para muitos, a imagem do resultado da relação entre eles.

Os subsídios teórico-clínicos, que sustentam a psicanálise aplicada a bebês em situação de risco psíquico (autismo e outras psicopatologias graves) garantem compreensão de que, esse risco se configura por meio de sinais das dificuldades do estabelecimento de uma relação entre o bebê e seu agente maternante ${ }^{7,8}$. Esse fato possivelmente restringe a singularidade subjetiva.

O objetivo desse artigo é refletir sobre uma faceta da constituição da relação mãe-bebê, que se fez presente no uso criativo da voz cantada da mãe, na comunicação com o seu bebê.

\section{APRESENTAÇÃO DO CASO}

Este estudo contou com a participação de um único sujeito, identificada pelo pseudônimo Thais (36), casada, executiva de uma multinacional, que tem em seu currículo uma incursão pela música erudita, influenciada por sua irmã gêmea (bi-vitelino), que exerce a profissão de cantora lírica fora do país.

Thais foi recomendada para tratamento corporal em decorrência de dores nas costas e disfonias. Ela foi indicada por uma amiga (psicanalista) que fora tratada pelo mesmo terapeuta e que está satisfeita, porque obteve sucesso no tratamento.

Todos os procedimentos foram realizados em domicílio. Esta condição facilitou a coleta de dados, bem como, avaliação da interação do sujeito da pesquisa com as pessoas e o ambiente em que vive.

O tratamento transcorreu em oito sessões; teve em média uma hora e trinta minutos por sessão; sob a orientação do terapeuta corporal. Constam, desse tratamento, manobras de torção e rotação do tronco para alongar as fibras musculares e re-posicionar as articulações; massagens para retirar a tensão excessiva da musculatura; exercícios para re-equilibrar a postura e coordenar os gestos; vivências para estimular a propriocepção e auto-análise (percussão nos ossos e toques sutis na pele). A partir da quarta sessão utilizou-se de recursos sonoros da voz cantada (exercícios melódicos em bocca chiusa, cantigas de ninar e músicas do repertório da mãe).

A terapia corporal em questão é norteada pelo método de reestruturação das cadeias musculares e articulares postulado por Godelieve Denys-Struyf (GDS) ${ }^{9}$. Este método auxilia a investigação dos problemas corporais, tais como: dores, problemas posturais, incoordenação do gesto, da respiração e da articulação de palavras, dentre outros. Uma vez reconhecido tais problemas tem-se a intenção de descobrir a possível etiologia, em consequência disso, fazer um prognóstico de tratamento.

Parte-se do pressuposto que estes problemas interferem na condição da saúde corporal e psíquica do sujeito, quer seja na presença ou não de uma patologia, e que podem ocasionar dificuldades na comunicação.

Os procedimentos do tratamento obedecem a seguinte ordem:

- Anamnese;

- Leitura corporal: esta leitura recebe o nome de "análise flash" (análise rápida, a primeira vista), nela são avaliados os gestos e a postura dos pacientes.

- Avaliação das queixas e dos exames médicos (quando houver);

- Execução de exercícios e manobras corporais que atendam às demandas oriundas da avaliação obtida na primeira abordagem, que configuram o tratamento propriamente dito.

Após cada sessão o terapeuta fez um relatório. Encontram-se descritas nesses relatórios as reações do sujeito da pesquisa frente ao tratamento. Isso favoreceu a avaliação e acompanhamento do caso, que possibilitou o uso do gesto criativo ${ }^{1}$ por meio da voz cantada, denominado neste artigo como uso criativo da voz cantada. Esse recurso configurou-se na exploração do repertório musical da mãe, com possibilidade de modificações dos pontos de ressonância, de projeção, de ajustes no pitch e loudness da voz, que estão apresentados no item resultados.

Esse estudo foi aprovado pelo Comitê de Ética em Pesquisa do Programa de Estudos Pósgraduados em Fonoaudiologia PUC-SP, sob o no 055/2007.

\section{RESULTADOS}

O primeiro contato com o sujeito deste estudo foi via telefone com a seguinte recomendação: "minha amiga me disse que você vai saber tirar minhas dores das costas e melhorar minha voz, estou contando com sua ajuda". 
O primeiro atendimento foi confirmado para uma quinta-feira às $10 \mathrm{~h}$. Porém a paciente não se encontrava em casa no horário marcado. Uma babá (com um bebê no colo) abriu a porta e pediu desculpas, em nome da sua patroa, que tinha saído para uma caminhada. Somente naquele momento soube-se que Thais dera a luz, a um menino, há oito dias.

Passaram-se 15 minutos e Thais chegou de sua caminhada. Educadamente, enfatizou seu pedido de desculpas. Justificou a necessidade de caminhar todos os dias para aliviar as tensões e as dores nas costas. Apesar de ser muito elegante (alta, magra, sem barriga), ela apresentava uma postura corporal arqueada, sua coluna comportava-se em cifose e sua bacia retrovertida, relatou uns sintomas de enjôo - parecia, ainda, estar grávida.

Ao iniciar a anamnese, houve uma "avalanche" de reclamações. Thais se dizia muito cansada de ficar em casa (estava de licença maternidade há um mês), reclamava que sua rotina era enfadonha e que as dores nas costas fizeram seu leite secar, por isso não conseguia amamentar. O Bebê se alimentava de leite em pó.

Neste momento o Bebê começou a chorar, e a ela disse:

- "Não aguento mais, ele chora o dia inteiro, nem a noite, quando meu marido chega ele da sossego, não sei mais o que fazer"; e na sequência deu ordem a babá para que tomasse as providências.

Quando indagada: Como foi o parto?

Ela prontamente respondeu:

- "Ótimo! Fiz uma cesariana super tranquila, minha cicatrização é muito boa, logo, logo vou poder malhar de novo na academia".

Nota-se que quando ela relatou seu parto, em nenhum momento se referiu ao bebê. Tampouco fez qualquer movimento para acalentá-lo.

Na primeira consulta, costuma-se não controlar o tempo, para obter mais informações. Após uma hora e dez minutos de conversa, propôs-se a execução de alguns exercícios, neste momento avaliou-se a flexibilidade muscular; a disposição para executar tarefas, e a propriocepção da paciente. Em seguida fez-se algumas manipulações nas costas, ombros, braços e pernas para ter um diagnóstico da tensão e da disposição das fibras musculares. Observou-se que a musculatura estava forte e sem grandes tensões que justificassem as reclamações das dores.

Ao final desta sessão ela se dizia mais aliviada, porém, segundo ela, parecia que a dor queria voltar.

- "Eu sei que você sabe o que eu tenho. Quando isto vai passar? Isto volta? Será que é alguma coisa?" (fazendo alusão a algo mais grave).
Sempre é alguma coisa, porém é necessário investigar, para se saber o que. Entretanto, houve uma devolutiva, algumas características foram apontadas, tais como: cifose dorsal, a cabeça avança para frente, a bacia retrovertida, os pés muito separados e os joelhos em $X$ (excesso de rotação interna da coxa). Todavia, essas características pareciam recentes, momentâneas, pois outras características anatômicas mostravam dados contrários ao que se apresentavam naquele momento, como: as curvas nos colos dos pés (padrão pouco comum em pessoas que tem joelho em X); a coluna, embora em cifose, apresentava uma extensão axial (coluna alongada no sentido da articulação atlas/áxis, onde os espaços intervertebrais estavam preservados).

Thais manifestou interesse em fazer duas sessões por semana, porque pretendia voltar ao trabaIho antes de terminar a licença maternidade. Essa intenção foi acatada.

Na segunda sessão, ela referiu melhora na disposição física, porém a dor estava presente. Contou que o bebê piorou, que chorou muito e cada vez mais forte, levaram-no ao pediatra porque apareceu uma hérnia no umbigo, que segundo o médico era de tanto chorar.

Este foi o primeiro momento, que ela falou do bebê. Diante disso, perguntou-se como tinha sido a gestação? Imediatamente ela perguntou: por quê? Seria muito importante que ela contasse tudo sobre a gravidez, porque todas as circunstâncias e as experiências, pelas quais havia passado, eram significativas, para que se pudesse compreender a respeito da dor que sentia.

Neste momento, fez-se um silêncio. Muito reticente ela contou que antes de engravidar não tinha nenhuma dor.

- "Vou te contar uma coisa" (fez uma longa pausa [...], seu semblante mudou completamente).

- "Sabe! Esta foi a minha segunda gravidez [...] há dois anos atrás eu engravidei [...]. Foi uma felicidade geral, nós não nos contivemos e antes da confirmação médica contamos para toda a família e amigos. Depois de confirmado fizemos uma grande festa; compramos o enxoval do bebê, chamamos uma decoradora para reformar o quarto do bebê; acertamos com a minha babá" (referindo-se a babá, já muito idosa, que cuidou dela quando nascera). Tudo perfeito para a primeira gravidez de um casamento de oito anos.

- "Porém, ao completar nona semana de gestação eu tive um pequeno sangramento, fomos direto para o pronto socorro e no caminho chamei pela minha ginecologista e obstetra, que chegou no hospital ao mesmo tempo em que eu e meu marido. Para nossa tristeza, ela disse que eu corria risco de aborto". 
Ao relatar esse fato ela segurava a barriga, como se estivesse protegendo um bebê dentro de si. Esse comportamento justificava ou dava pistas para a compreensão da postura arqueada que ela apresentava

- "Infelizmente, após uma semana de repouso absoluto, abortei".

O aborto espontâneo sofrido por Thais coincide com o período de risco descrito em uma pesquisa ${ }^{10}$, que avaliou as condições de vida intra-uterina. Tal pesquisa demonstrou que a detecção tardia da frequência cardíaca, bem como alterações na frequência podem revelar as prováveis causas de abortos espontâneos no primeiro trimestre de gestação.

A sessão estava muito tensa e triste, porém ela queria falar.

- "Sabe! (tentava parar o choro para se recompor, mas não conseguia) Eu me sentia suja por ter feito um aborto, parecia que meu útero não era saudável, tinha sensação de contaminação, e que eu tinha passado aquilo para o meu bebê, por isso ele morreu. (ela interrompia sua fala porque o bebê, no quarto do piso superior, chorava muito) Será que é cólica? Disseram-me que vai até o terceiro mês, espero que não, se não enlouqueço".

Tudo o que ela contava, sobre a relação dela com o bebê, parecia muito distante, aliás, parecia não haver nenhuma relação entre eles. Não se sabia, até então, se ela tinha segurado o bebê no colo, ou se tinha conversado com ele.

O choro do bebê era muito forte, imaginava-se que aquele choro era a representação de um padecimento pela ausência da mãe ${ }^{11}$.

Novamente a sessão terminou sem que se tivesse estabelecido um prognóstico para o tratamento. A necessidade que ela tinha de falar sobre aquele assunto era tamanha, que a melhor conduta foi escutá-la, ainda que para isso o tempo programado para atividade corporal ficasse prejudicado. Importava é que ela queria dar lugar à fala.

$\mathrm{Na}$ terceira sessão, retomou-se o assunto sobre a gestação. Pois, na sessão anterior ela relatou tudo sobre sua primeira gestação (interrompida), e nada foi mencionado sobre esta gravidez e o bebê. Ela começou a sessão com reclamações.

- "Ele não me deixou dormir, chorou a noite toda, acho que preciso trocar de babá, esta que está com ele é muito experiente, mas não está dando conta".

- "O que mais você quer saber? Eu já te disse tudo na ultima sessão?".

Foi uma gestação tranquila? Você ficou feliz? Como foi o parto? Essas perguntas tinham um propósito bem marcado. Conduzi-la a uma reflexão, para que percebesse que, ainda, não tinha estabelecido uma relação com o bebê, e esta ausência podia ser a causa do choro compulsivo dele. Mas também, tinha o propósito de se certificar que as manifestações apresentadas se encaixavam com um quadro típico de depressão pós-parto ${ }^{11,12}$.

Ela relatou que não acreditava na possibilidade de engravidar novamente, e em nenhum momento achou que a gravidez chegaria até o nascimento. Preferiu não se animar, pois sabia que a qualquer hora teria um aborto espontâneo. E foi assim durante os nove meses de gestação. Porém...

- "Um desejo interno me levou a fazer um treinamento para ter um parto natural. Pura ilusão, pois eu sabia que não ia dar certo. Dito e feito, quando eu entrei em trabalho de parto não tive dilatação suficiente, a médica disse que faríamos uma cesariana, naquele momento eu acreditei que o bebê ia morrer".

Entretanto, para surpresa de Thais, o bebê nascera, forte e sem qualquer complicação. Mesmo assim, ela não conseguiu estabelecer contado com ele e não o enxergava como seu.

Diante desta realidade, refletiu-se, que a única condição para que aquela mãe acreditasse que seu bebê nascera e que precisava dela, era dar ao seu corpo uma condição de realização do parto, de sensibilização e completude. Propôs-se então, uma simulação de trabalho de parto.

Solicitou-se que ficasse em decúbito lateral, que se concentrasse no nascimento do bebê e exercitasse a respiração, tal qual é trabalhado nos cursos para gestantes, ou seja, inspiração nasal profunda diafragmática seguida de expiração oral frenolabial ${ }^{13}$. Esta é a respiração específica para os intervalos entre as contrações do trabalho de parto. A prática respiratória durou oito minutos.

Sem dúvida nenhuma, esta foi uma experiência muito forte. Ela precisava desta experiência, pois seu corpo inteiro participou. Seu empenho foi muito grande, ela mergulhou naquela sensação, sua respiração se alterou, de tal modo, que a transpiração foi inevitável. Ela se transportou no tempo, dando vazão a uma necessidade que parecia atávica.

Ao final da sessão agradeceu, muito emocionada, e sem que se dissesse qualquer coisa, ela concluiu:

- "Agora eu posso pegar o meu bebê, ele nasceu!"

Finalizou-se a sessão com a sensação de missão cumprida, pois Thais estava com um semblante mais tranquilo e com um brilho diferente no olhar.

Na sessão seguinte (quarta sessão), Thais esperava na sala nitidamente ansiosa, roía as unhas e num tom lamurioso disse:

- "Você não sabe! Ele não me quer, só quer a babá. Fui pegá-lo, mas não consegui, ele não parou de chorar. Agora que achei que estava tudo resolvido [...] não sei mais o que fazer". 
Naquele momento, a ansiedade, a impedia de compreendê-lo e seu olhar voltava-se sempre para si mesma. Ela não era capaz de dar condição de sujeito ao seu bebê, por isso não o percebia com necessidades próprias ${ }^{14}$.

Sabia-se que a ausência da mãe poderia provocar alterações na criança, e acreditava-se na possibilidade de reverter àquela situação, pois a transferência estava estabelecida ${ }^{15}$. Mas o que fazer? Talvez promover aproximação dos dois, mas como?

Nesse momento, com um gesto criativo, solicitou-se à babá que trouxesse o bebê e que o colocasse no chão, no mesmo nível da mãe, sobre um colchão. Em seguida solicitou-se à mãe que cantasse para o bebê.

Essa atividade teve como propósito promover a aproximação da mãe com o bebê, para que ele pudesse reconhecê-la e desejá-la.

A princípio, ela achou muito difícil, disse que sua voz já não era a mesma, que há muito tempo não cantava. Orientou-se que não se preocupasse com a estética, mas sim, com a intenção, que cantasse com alma, com emoção independente da letra ou da melodia. Nesse contexto cantar é potencializar a comunicação, é criar de fato a presença ${ }^{16}$.

Recomendou-se, que primeiramente, cantasse com bocca chiusa, deitada no chão em decúbito lateral, para que não houvesse uma sobrecarga de tensão na musculatura do pescoço, ombros, peitoral, etc. e, também para que ela pudesse escutar sua própria voz, produzida no seu corpo inteiro.

Em seguida, iniciaram-se algumas cantigas de ninar e pediu que ela acompanhasse.

Ela estava muito resistente, mas aos poucos se soltou. Sua voz soava muito tímida, porém percebia-se a ressonância equilibrada, pitch agudo, a voz clara.

Aos poucos sem que ela percebesse, cantou sozinha e quando ela se deu conta, o bebê não mais chorava. Esse momento foi de grande surpresa e satisfação, para ambos. Mãe e bebê pareciam mais tranquilos e se comunicaram pela primeira vez.

Para finalizar a sessão, propôs-se que ficasse em decúbito dorsal, que espreguiçasse, para alongar lentamente todo o corpo, para depois se levantar.

Na semana seguinte (quinta sessão), Thais contou que cantara todos os dias para o bebê, e ele com certeza estava melhor.

- "Ele parou de chorar. Eu até fiquei com vontade de pegá-lo no colo, mas eu não sei, eu tenho medo".

Alguns exercícios de aquecimento e flexibilização da musculatura foram propostos, associados a passos de danças e gestos livres (espontâneos).
Novamente o bebê esteve presente na sessão, porém desta vez solicitou-se que ela pegasse 0 bebê e cantasse para ele.

Embora com muita dificuldade e medo, seu corpo todo se ajeitou para segurar o bebê, e ele se moldou ao colo da mãe.

A voz da mãe parecia um alívio para o sofrimento do bebê, seu semblante era tranquilo. Após algumas cantigas ele dormiu sossegado, enquanto ela chorava emocionada.

Passado uma semana (sexta sessão) Thais atendera à porta com o bebê no colo. Ele dormia tranquilamente.

O sorriso estampado no rosto daquela mãe era algo digno de uma pintura. Thais sussurrava as palavras, porque tinha medo de acordar seu bebê e perder aquele momento encantado.

- "Consegui cantar para ele todos os dias, tenho certeza que ele gosta, pois, toda vez que eu canto, ele fica atento para me ouvir".

Toda orgulhosa disse:

- "Ele tem bom gosto para música. Cantei Summertime (Gershwin) e esta parece ser a sua música predileta".

Após duas sessões, ela mesma "se deu alta", pois se considerava re-estabelecida, pronta para assumir o trabalho e retornar às "atividades normais".

É evidente que era cedo, para que se soubesse a estabilidade constituída na relação mãe-bebê, mas sem dúvida alguma, era um começo promissor.

\section{DISCUSSÃO}

Esse caso sugere que outros tipos de intervenções, inclusive, com e para o bebê poderiam ser adotadas. Embora as manifestações e as demandas estivessem marcadas como representações corporais, faz-se várias conjecturas sobre a chegada deste bebê no mundo; tais como: as maneiras pelas quais foi recebido e cuidado; as suas precoces vicissitudes de abandono e rejeição.

As dificuldades vivenciadas pela mãe no cuidado com o seu bebê, sem conseguir se aproximar dele, nem segurá-lo, em um momento inicial da relação, pode desencadear no bebê uma enorme sensação de desconforto; de falta de proteção corporal, levando-o a uma possível desilusão precoce, uma vez que nessa idade o bebê não tem condições de lidar com esta situação ${ }^{15}$.

Provavelmente a desilusão que esta mãe acometeu ao seu bebê, a primeira desilusão, de modo direto, tenha implicação na constituição e evolução do self do bebê. Esta desilusão precoce cria a experiência de alteridade, antes que ele esteja preparado para lidar com essa modalidade de experiência ${ }^{15,17}$. 
Esse caso apresenta a impossibilidade momentânea da mãe em ofertar holding para o seu bebê ${ }^{15,18}$, ou seja, uma oferta do cuidado materno, que possibilita o bebê, aos poucos, alcançar uma experiência de lugar. Essa impossibilidade foi representada pela falta de colo e de amamentação, fato que resultou na falta de comunicação entre eles, e que possivelmente está atrelada às dores corporais e à perda de voz da mãe ${ }^{1,2}$.

Embora não se soubesse o caminho a trilhar com esta mãe, tinha-se a certeza de poder ajudála, pois seus medos, necessidades e dificuldades foram partilhados, na transferência ${ }^{15}$, com isso, criaram-se condições, para que ela encontrasse o que tanto buscava, isto é, condições para se comunicar com seu bebê ${ }^{4}$.

Os desbloqueios das tensões musculares aliviaram as dores e liberam os gestos, isso possibilitou novas sensações de movimentos, de manutenção da postura e garantiram uma atualização proprioceptiva ${ }^{9}$, isto é tornaram-se presentes sensações corporais que não estavam trabalhadas, devido excesso de tensão e medo.

A simulação do nascimento (gesto corporal) proporcionou uma vivência de sensações semelhante às do parto. Essa dinâmica completou um ciclo e um movimento que precisava ser expresso, para que ela se aproximasse do bebê e o reconhecesse como filho.

O uso criativo da voz cantada, isto é, a exploração do repertório musical da mãe, com variações rítmicas e modificações na ressonância, projeção, pitch e loudness possibilitou a reestruturação da propriocepção da voz da mãe. Esse gesto surgiu como um movimento pessoal expansivo, inicialmente dirigido a um objeto subjetivo (no espaço) e depois ao Outro, o bebê, e configurou-se em um veículo de comunicação e reconhecimento entre eles ${ }^{1}$.

O canto entoado pela mãe teve efeito calmante para bebê. Toda vez que ela cantou uma melodia ou uma canção, ele parou de chorar. Parecia que ele reconhecia e necessitava daquela voz, talvez para se identificar e com isso se sentir seguro e protegido, fator primordial na constituição de uma personalidade saudável ${ }^{1,14}$.

Provavelmente as entoações melódicas propiciaram à mãe uma possibilidade de movimentos corporais e ritmos, que serviram para embalar o bebê e garantiram sensações de conforto e de prazer recíprocos.

\section{CONCLUSÃO}

Considera-se como elemento significativo, nos resultados deste estudo, a possibilidade de reconhecimento entre mãe e bebê, que ocorreu por meio do uso criativo da voz cantada. A corporeidade teve papel importante na conjunção dos corpos, pois estabeleceu uma comunicação com sintonia de ritmos, conquistada pela entoação do canto e que favoreceu a constituição do bebê enquanto pessoa integrada.

\begin{abstract}
Background: to address one aspect of mother/baby relationship, that arises from the use of singing voice in their communicative process. Procedure: the subject of this case study is a mother who undergoes eight sessions of body therapy (massage and exercises) associated to the utterance of singing voice, always directed to the baby; the sessions offered the possibility of free expression through the mother's use of gestures and speech along with the therapist' listening. Results: in the beginning of treatment, the reaction of the mother towards her baby fits precisely in postpartum depression description. After the sessions, she was able to keep a most pleasant contact with her baby; by means of the singing voice, she has got the first way of communication with her child and either pain or temporary lack of voice have disappeared. Conclusion: the mother's baby acknowledgement had the two bodies' liaison as allied, which made possible the settlement of a rhythm tuned communication by means of singing music intonation, which led to the possibility of an emotional integration and development of the baby.
\end{abstract}

KEYWORDS: Mother-Child Relations; Infant, Newborn; Communication; Voice 


\section{REFERÊNCIAS}

1. Winnicott DW. Mãe dedicada comum. In: Winnicott DW. Os bebês e suas mães. 2. ed. São Paulo: Martins Fontes; 2002. p.1-11.

2. laconelli V. Depressão pós-parto, psicose pósparto e tristeza materna. Rev Pediatr Modern. 2005; 41(4):210-1.

3. Böeing E, Crepaldi MA. Os efeitos do abandono para o desenvolvimento psicológico de bebês e a maternagem como fator de proteção. Rev Est Psicol. 2004; 21(3):211-26.

4. Laznik MC, Maestro S, Muratori F, Parlato E. Interações sonoras entre bebês que se tornaram autistas e seus pais. An Col Franco-Bras sobre a Clínica com Bebês. Jan, 2005; Paris. [proceedings online] Disponível em: URL: http://www.proceedings. scielo.br/scielo.php?script=sci-arttext\&pid=MSC $0000000072005000100004 \&$ lng $=e n \& n r m=a b n>$. Acesso em 10 Set 2007.

5. Burnham D, Kitamura C, Vollmer-Conna U. What's new pussycat? On talking to babies and animals. Science. 2002; 296(5572):1435.

6. Kaplan PS, Sliter JK, Burgess AP. Infant-directed speech produced by fathers with symptoms of depression: effects on infant associative learning in a conditioned-attention paradigm. Infant Behav Dev. 2007; 30(4):535-45

7. Campanário IS, Pinto JM. O atendimento psicanalítico do bebê com risco de autismo e de outras graves psicopatologias. Uma clínica da antecipação do sujeito. Estilos Clin. 2006; 11(21):150-69.

8. Pinto EB. Baby's psychofunctional symptoms and parents/baby therapeutic consultations. Estud Psicol. 2004; 9(3):451-7.
9. Denys-Struyf G. Cadeias musculares e articulares. São Paulo: Summus; 1995.

10. Achiron R, Tadmor O, Mashiach S. Heart rate as a predictor of first-trimester spontaneous abortion after ultrasound-proven viability. Obstet Gynecol. 1991; 78(3Pt1):330-4.

11. Paulson JF, Dauber S, Leiferman JA. Individual and combined effects of postpartum depression in mothers and fathers on parenting behavior. Pediatrics. 2006; 118(2):659-68.

12. Nicholson WK, Setse R, Hill-Briggs F, Strobino D, Cooper LA, Powe NR. Depressive symptoms and health-related quality of life in early pregnancy. Obstet Gynecol. 2006; 107:798-806.

13. De Conti MHS, Calderon IMP, Consonni EB, Prevedel TTS, Dalbem I, Rudge MVC. Efeito de técnicas fisioterápicas sobre os desconfortos músculos-esqueléticos da gestação. Rev Bras Ginecol Obstet. 2003; 25(9):647-54.

14. Tahan LG, Maia SM. A função terapêutica em fonoaudiologia. Rev Dist Comun Hum. 2005; 17(1):115-21.

15. Pinheiro MG, Cunha MC. Voz e psiquismo. Rev Dist Comun. 2004; 16(1):83-91.

16. Andrada e Silva MA, Duprat A. Voz cantada. In Ferreira LP, organizador. Tratado de fonoaudiologia. São Paulo: Rocca; 2004. p. 178-94.

17. Kumin IM. The piggle: an account of the psychoanalytic treatment of a little girl: D. W. Winnicott, International Universal Press, New York, 1977, 201pp.,\$10.00. J Am Acad Psychoanal. 1979; 7:453-5.

18. Ginot E. The holding environment and intersubjectivity. Psychoanal Q. 2001; 70(2):417-46.
DOI: 10.1590 / S1516- 18462009005000006

RECEBIDO EM: 21/12/2007

ACEITO EM: 19/04/2008

Endereço para correspondência:

Enio Lopes Mello

Rua Juréia, 394 ap. 161

São Paulo - SP

CEP: 04140-110

E-mail: enio.mello@superig.com.br 